\title{
Configuration Optimization of Cables in Ductbank Based on Their Ampacity
}

\author{
Bin Sun, Elham Makram \\ Electrical and Computer Engineering Department, Clemson University, Clemson, USA \\ Email: bins@clemson.edu
}

How to cite this paper: Sun, B. and $\mathrm{Ma}$ kram, E. (2018) Configuration Optimization of Cables in Ductbank Based on Their Ampacity. Journal of Power and Energy Engineering, 6, 1-15. https://doi.org/10.4236/jpee.2018.64001

Received: March 22, 2018

Accepted: April 27, 2018

Published: April 30, 2018

Copyright ( 2018 by authors and Scientific Research Publishing Inc. This work is licensed under the Creative Commons Attribution International License (CC BY 4.0).

http://creativecommons.org/licenses/by/4.0/ (c) (i) Open Access

\begin{abstract}
Electrical power companies are using more underground cables rather than overhead lines to distribute power to their customers. In practice, cables are generally installed in some compact ductbanks. Since the cost of underground cables is very expensive, using the entire space of a ductbank is extremely important. But such usage is limited due to the overheating of cables. Overheating is generally caused by overload, which means the carrying current exceeds the ampacity of a cable. The ampacity of a cable depends on not only the material and design of a cable but also the distance between different cables. Thus the configuration of cables determines the total ampacity value and the potential use of a ductbank. In this paper, the best configuration based on ampacity is achieved for a three-row, five-column ductbank that is buried at a depth of one meter below the earth's surface. Both balanced and unbalanced scenarios are considered, and all cables have two available types to be selected.
\end{abstract}

\section{Keywords}

Configuration Optimization, Underground Cables, Ampacity, Balanced, Unbalanced

\section{Introduction}

Underground cables have more advantages than overhead lines since cables offer better protection and are not as unsightly in appearance in urban areas. In practice, cables are generally installed in some compact ductbanks in order to provide easier installation of multiple cables in a concrete space [1], as shown in Figure 1. However, installation and maintenance of underground cables are a lot more expensive compared with overhead lines [2]. According to [3], the cost of laying the cables is $\$ 125$ - $\$ 200$ per meter. Thus it is extremely critical to use the full potential of the ductbank. However such use is limited by the overheating of 


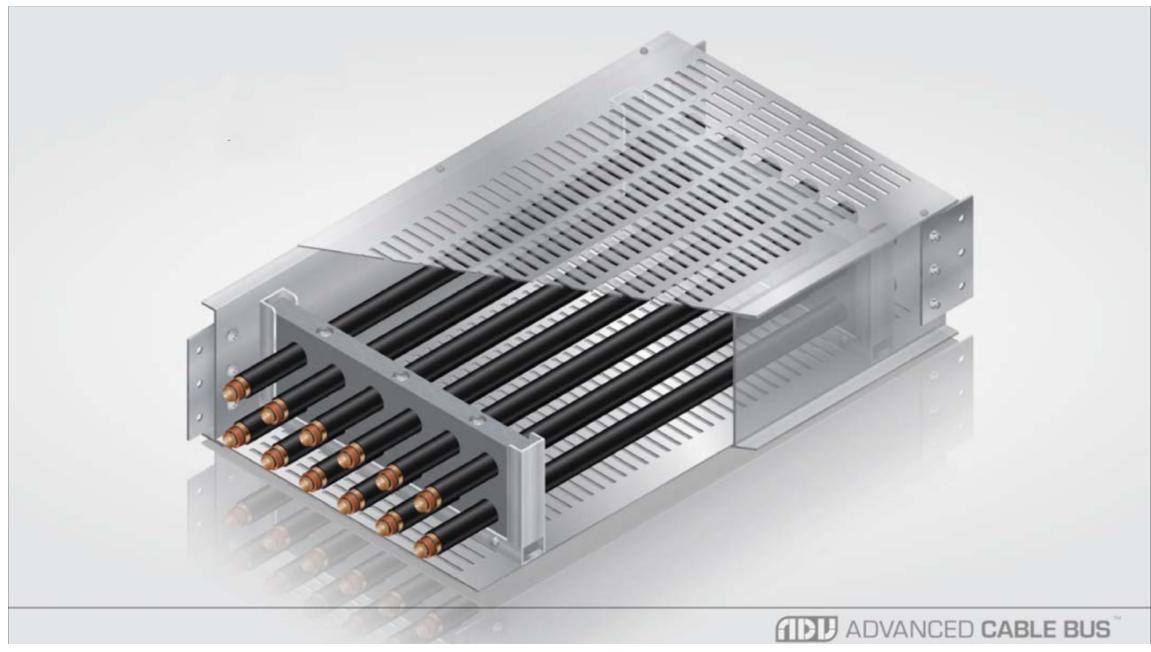

Figure 1. Cables in a ductbank for installation [9].

cables. Overheating is the most significant factor in decreasing cable service life [4]. Since cables are surrounded by soil instead of air, the speed of temperature diffusion is much slower than in air [4]. The high currents carried by cable conductors are usually the cause of high temperatures. Overheating of cables generally results by overloading them [5]. Each cable has a current limitation, called ampacity [4], that allows the cable to operate without problems. When the carrying current exceeds its ampacity, cable damage results, followed by failure that may be difficult to fix. Ampacity depends on the strength of the heat source, the material of cables, and the surrounding environment, including the ductbank and soil [5]. When the thermal resistance of cable layers and soil is low, the heat can spread faster, and the ampacity of the cable is higher. Conversely, higher thermal resistance can mean lower ampacity value.

However, a cable's ampacity value is decided not only by its own characteristics but also by neighboring cables. The heat generated by one cable can influence the maximum value of the current of one nearby. This influence is called the mutual heating effect [1]. In a ductbank, there are lots of available ducts that can be selected. So various cable configurations are possible. Different configurations cause different total ampacity value. The distance between two cables significantly influences ampacity value due to the mutual heating effect. So proper design of cable layout, i.e. using the entire space of a ductbank, can lead to maximum total current carrying capacity. Similarly, one cable configuration can offer only minimum total ampacity. This worst-case scenario is useful when a power system is being analyzed without knowing the exact layout of cables. Thus, the configuration optimization of cables in a ductbank is hugely crucial.

Although some researchers have studied cable configuration optimization [1] [5] [6] [7] [8], they covered only the three-phase balanced condition and only one type of cable. However, most distribution systems are dealing with unbalanced loading, and the selection of cables must consider various types and designs. The objective of this paper is to figure out the best configuration for deli- 
vering more current, if needed, in one ductbank and avoiding overheating of the cables under both balanced and unbalanced conditions based on types of cables.

\section{Methods of Analysis}

\subsection{Ampacity Calculation}

It is known that a cable's ampacity is based on the highest allowable temperature that cable can hold without overheating, and it is influenced by the mutual heating effect of nearby cables. To properly design a cable system and optimize cable configuration, calculating the ampacity value of various cables with different cross-sections and sizes is extremely important. Typically, an underground cable consists of four layers, including a conductor layer, insulation layer, shield layer, and jacket layer [10]. This paper used COMSOL [11], which is a powerful multi-physics simulation software, to model a shielded cable, as shown in Figure 2.

Several publications proposed different methods to calculate cables' parameters and their ampacities for both single and multiple cable configurations [12] [13] [14] [15]. Among these publications, two of them are widely used: the Neher and McGrath method [16] and IEC Standards 287-3-2 [17]. These two methods are similar. They summarize all existing principles and equations to calculate cable ampacity in different conditions, including single cable, multiple cables without ductbank, and multiple cables with ductbank. These two methods

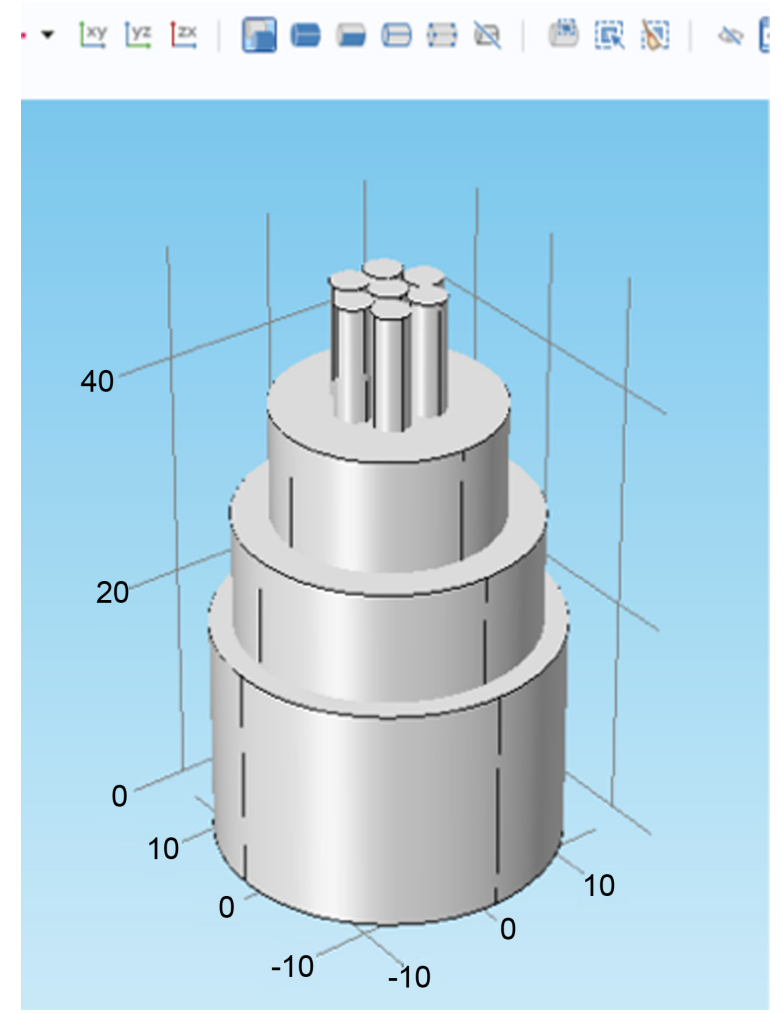

Figure 2. Common layers arrangement of cables simulated in COMSOL. 
are then classified and summarized by Dr. George J. Anders [4], as shown below.

In order to calculate the ampacity of cable $i$, a thermal circuit includes heating sources, and the thermal resistance of different layers is built based on the highest allowable cable temperature.

$$
\begin{gathered}
I_{i}=\left[\frac{\Delta \theta_{\max }-W_{d}\left(0.5 T_{1}+n\left(T_{2}+T_{3}+T_{4}\right)-\Delta \theta_{i n t}\right)}{R T_{1}+n R\left(1+\lambda_{1}\right) T_{2}+n R\left(1+\lambda_{1}+\lambda_{2}\right)\left(T_{3}+T_{4}\right)}\right]^{0.5} \\
\Delta \theta_{\max }=\theta_{\max }-\theta_{a m b} \\
\Delta \theta_{i j}=W_{j} * T_{i j} \\
\Delta \theta_{i n t}=\sum_{j=1}^{N} \Delta \theta_{i j} \\
W_{j}=n\left[I_{j}^{2} R_{j}\left(1+\lambda_{1}+\lambda_{2}\right) \mu_{j}+W_{d j}\right] \\
T_{i j}=\frac{\rho_{s}}{2 \pi} \ln \frac{d_{i j}^{\prime}}{d_{i j}}
\end{gathered}
$$

where $I_{i}$ is the ampacity of cable $i, I_{j}$ is the carrying current of cable $j, R_{i}$ is the AC resistance of cable $j, \lambda_{1}$ is cable j's shield loss factor, $\lambda_{1}$ is cable jacket loss factor, $\mathrm{n}$ is the conductors number, $\mu_{j}$ is the loss factor, $W_{d j}$ is the dielectric loss of cable $j, T_{1}, T_{2}, T_{3}, T_{4}$ are the thermal resistance of different layers including ductbank and soil, $\theta_{\max }$ is the highest temperature that allows the cable to operate without problems, $\theta_{a m b}$ is the ambient temperature, and $\Delta \theta_{i n t}$ is the reduction factor of conductor temperature. All these parameters depend only on the material and design of the cable and of the surrounding conditions [18]. The influence of mutual heating from nearby cables is corrected by $\Delta \theta_{\text {int }}$.

\subsection{Optimization of Cables in a Ductbank}

From the Equations (1)-(6) shown in Section 2.1, it can be noticed that to find the ampacity of cable $i$, carrying currents of all other cables should be pre-known, given the mutual heating effect. So if these equations are applied to all cables, a set of mutually interconnected equations is obtained. However, a set of interrelated equations is challenging to solve, and frequently, the iteration method can be used. But it is time-consuming, and not convergent in some conditions. So a more efficient method is the optimization method, which is recommended by Dr. Moutassem [5]. Finding the ampacity value of each cable for a specific configuration could be described as an optimization problem. The objective function is the sum of all carrying currents. The constraints are that the temperatures of all cables are smaller than the highest allowable temperatures. In this paper, the same equations are used to decide the best configuration based on ampacity for cables in a ductbank assumed a constant frequency system. The detailed transformation steps of this optimization problem are summarized in Appendix B.

The optimization problem for multiple cables installed in a ductbank for a specific configuration can be summarized as follows: 
The objective function is

$$
I_{1}+I_{2}+\cdots+I_{n}
$$

The constraint for cable 1 is:

$$
\frac{1}{d_{1}} I_{1}^{2}+\frac{C_{12}}{d_{1}} I_{2}^{2}+\cdots+\frac{c_{1 n}}{d_{1}} I_{n}^{2} \leq 1
$$

Similarly, the constraints for the other cables are:

$$
\frac{c_{i 1}}{d_{i}} I_{1}^{2}+\frac{c_{i 2}}{d_{i}} I_{2}^{2}+\cdots+\frac{1}{d_{i}} I_{i}^{2}+\cdots+\frac{c_{i n}}{d_{i}} I_{n}^{2} \leq 1
$$

Using MATLAB, the constraints can be acquired in a matrix form.

$$
c *\left(I^{2}\right)^{\prime} \cdot / d^{\prime}
$$

where all elements in matrices $c$ and $d$ are calculated based on Equations (13)-(14) in Appendix B and matrix c has one on its diagonal terms.

The procedure for finding the total ampacity value for a specific configuration of cables in a ductbank is completed. The next step is to find the configuration that leads to the maximum total ampacity value and minimum total ampacity value. The method applied in this paper includes three steps. Firstly, assume all ducts have their own cables with some initial guess as to current values. Secondly, randomly choose some of these cables to have current equal to zero, which means these ducts don't have cables installed in them. Thirdly, find the best and worst configuration that produces the maximum total ampacity value and minimum total ampacity value. But since, in this program, the types of cables should be selected automatically, one more step is added that introduces additional ducts for different cable types selection. The steps of configuration optimization of cables in a ductbank are shown in Figure 3.

In this paper, a three-row, five-column ductbank is selected. It is buried at a depth of one meter below the earth's surface. The distance between two ducts in the same row is 0.3 meter, and the distance between each row is 0.5 meter, which is shown in Figure 4. Both balanced and unbalanced conditions are considered. In a balanced scenario, all cables are equally loaded. For an unbalanced scenario, $I_{b}=1.05 I_{a}$ and $I_{c}=1.1 I_{a}$ are studied in detail as a particular example of unbalanced cases. Then the general patterns for unbalanced conditions are also obtained. In this paper, cables have two available types that can be selected. The detailed data of these two types of cables are listed in Appendix C.

\section{Results}

\subsection{Configuration Optimization for a Balanced Condition}

For two cables per phase, the second type of cable is selected, and the maximum ampacity of each cable is $655 \mathrm{~A}$, as shown in Figure 5(a). The minimum ampacity of each cable is 559 A, as shown in Figure 5(b). This configuration is reasonable since all cables are located near each other. So the heat generated by one 


\section{Configuration Optimization}

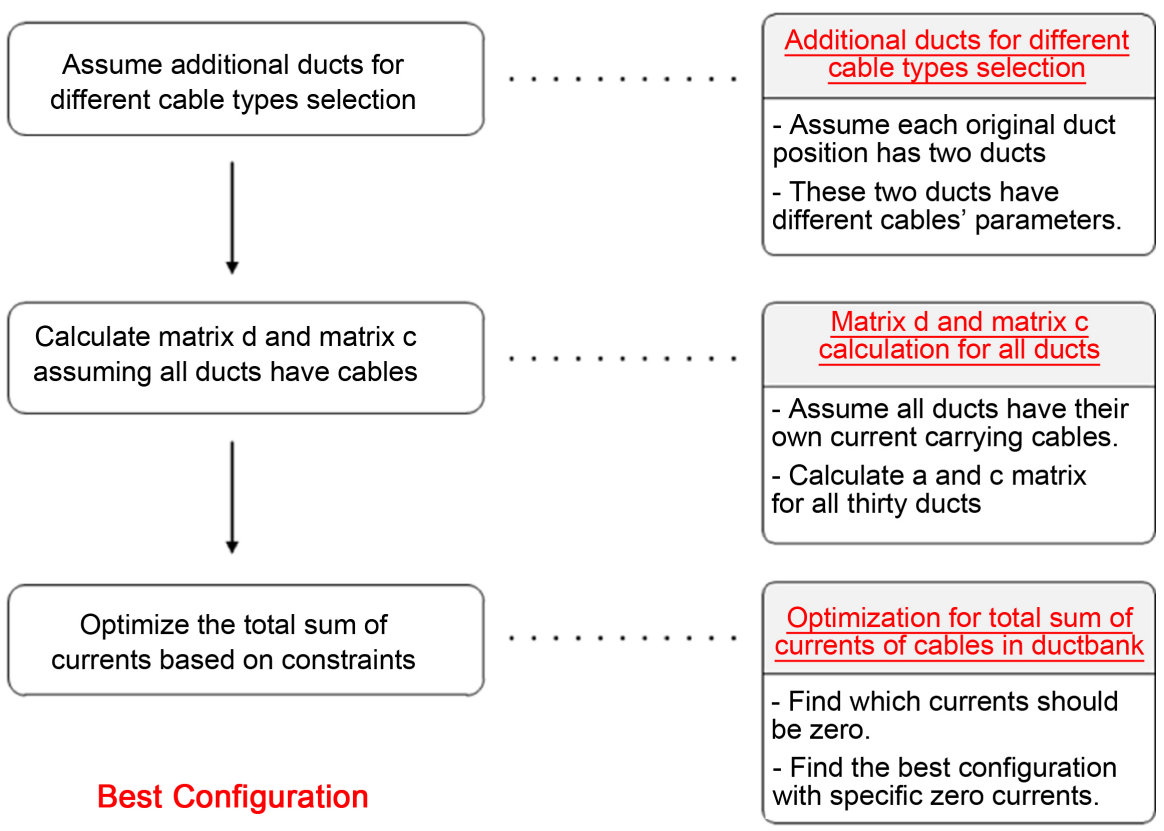

Figure 3. Procedure for configuration optimization of cables in a ductbank.

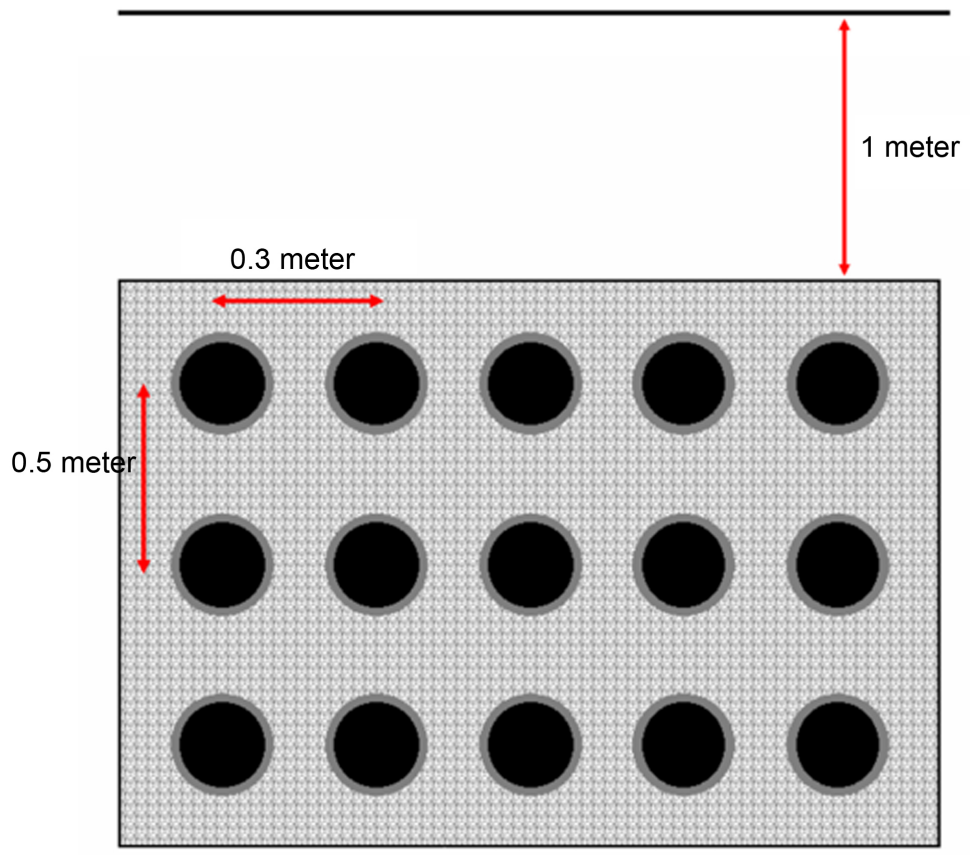

Figure 4. The configuration of ductbank simulated in CYMCAP [19].

cable has more influence on those nearby. Thus the total ampacity is smallest. The difference between these two values proves that configuration optimization for cables in a ductbank is very important.

Normally configuration in Figure 5(c) is applied if the common sense without 


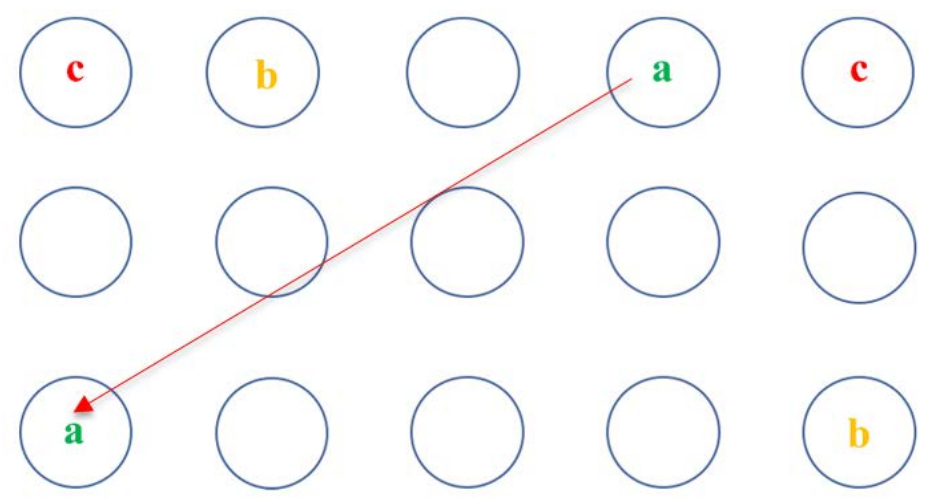

(a)
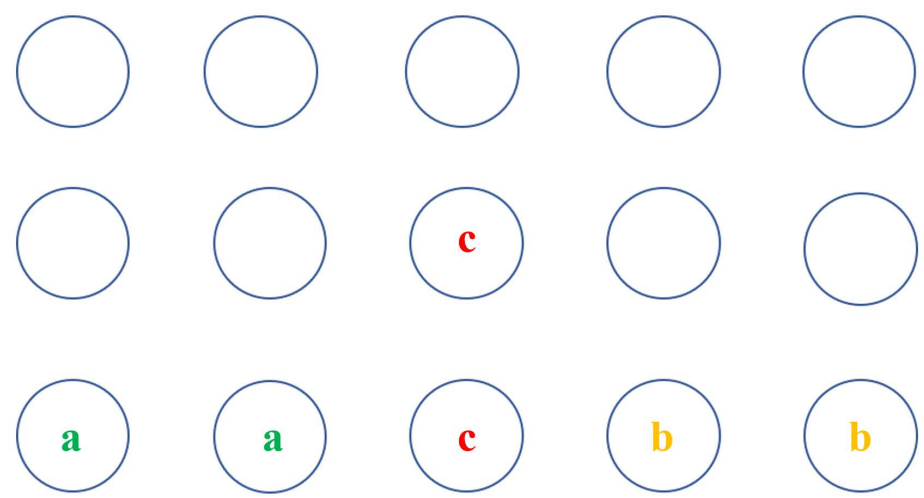

(b)


(c)

Figure 5. The optimization result compared with common sense for two balanced cables per phase. (a) Best configuration by optimization; (b) Worst configuration by optimization; (c) Common sense without optimization.

optimization is followed. These two results of ampacity values are compared. For configuration in Figure 5(c), the ampacity of each cable is $634 \mathrm{~A}$, which is smaller than the optimization result as shown in Figure 5(a). This difference can be easily explained by the distances between the cables in the two figures. At first glance, the distances between different cables in Figure 5(c) seem more significant than the distances in Figure 5(a). But if the configurations are analyzed 
carefully, an opposite conclusion can be reached. For example, the distance between the two cables of phase "a" in Figure 5(a) is longer than the distance between the two cables of phase "a" in Figure 5(c). Similar conclusions can be obtained in these two figures by comparing the distances between different cables. The conclusion is that the configuration of Figure 5(a) produces larger total ampacity than the configuration in Figure 5(c). The detailed results for maximum ampacity value are shown in Table 1.

The temperature limitation of type two cable is $90^{\circ} \mathrm{C}$ and the resulting temperatures of all cables are below $90^{\circ} \mathrm{C}$. Moreover, the temperatures of the cables are symmetric in Table 1 since the arrangement of cables is symmetric in the ductbank and the cables are in balanced condition.

For three cables per phase, the second type of cable is selected, and the maximum ampacity of every cable is $566 \mathrm{~A}$, which is shown in Figure 6(a). The minimum ampacity of each cable is $495 \mathrm{~A}$, which is shown in Figure 6(b). Similar to Figure 5(b), the configuration in which all cables are arranged together leads to the smallest total ampacity value. According to common sense without optimization, usually the configuration in Figure 6(c) is applied. For the configuration in Figure 6(c), the ampacity value of each cable is $541 \mathrm{~A}$, which is smaller than the optimization result. The detailed results for maximum ampacity value are shown in Table 2.

Table 1. Detailed results for two balanced cables per phase.

\begin{tabular}{cc}
\hline Cable \# & Temperature $^{\circ} \mathrm{C}$ \\
\hline 1a & 86.4 \\
2a & 89.8 \\
1b & 89.8 \\
2b & 86.4 \\
$1 \mathrm{c}$ & 84.9 \\
2c & 84.9 \\
\hline
\end{tabular}

Table 2. Detailed results for three balanced cables per phase.

\begin{tabular}{cc}
\hline Cable \# & Temperature ${ }^{\circ} \mathrm{C}$ \\
\hline la & 81.1 \\
2a & 87.4 \\
3a & 89.9 \\
1b & 89.4 \\
2b & 84.5 \\
3b & 89.7 \\
1c & 83.6 \\
2c & 89.8 \\
3c & 87.1 \\
\hline
\end{tabular}



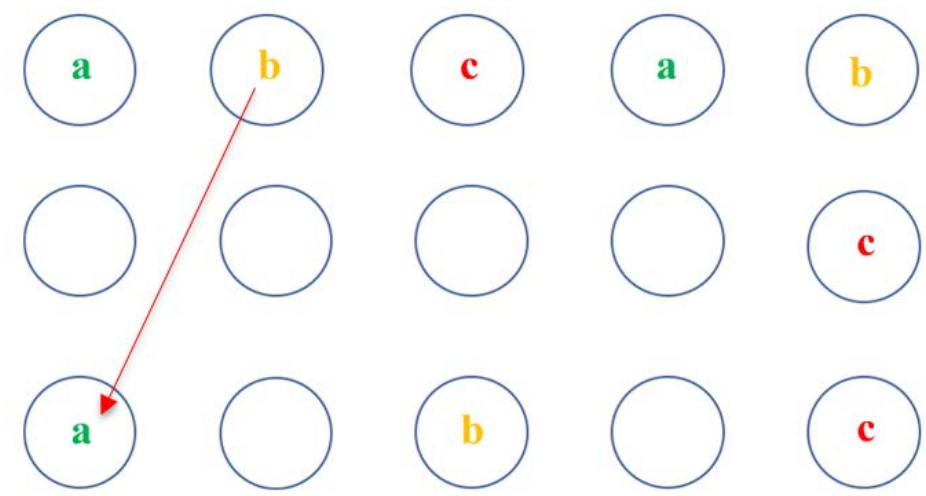

(a)
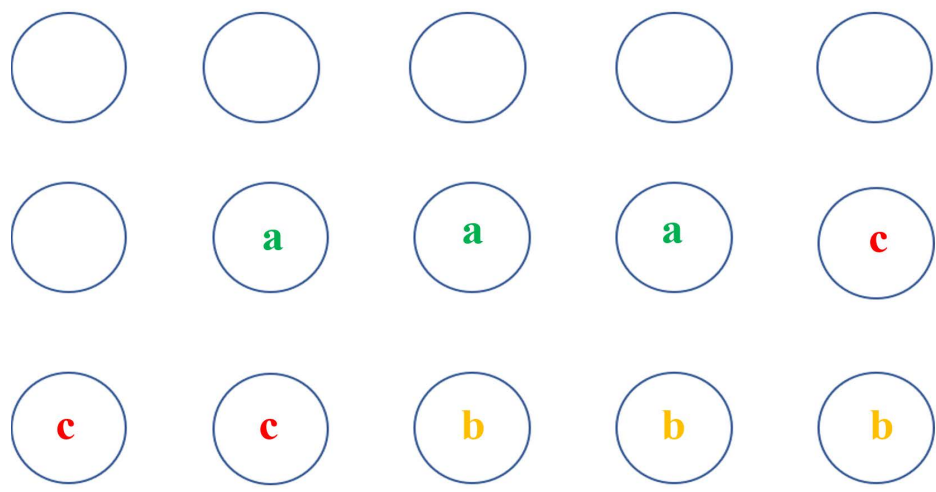

(b)
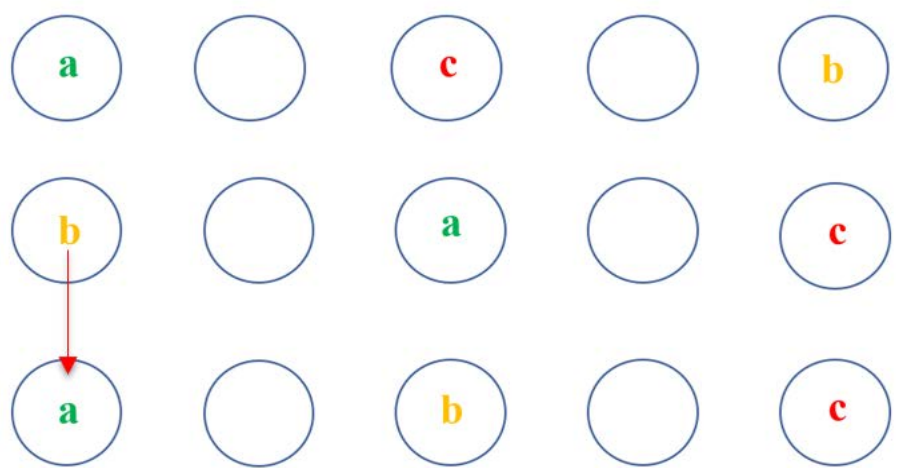

(c)

Figure 6. The optimization result compared with common sense for three balanced cables per phase. (a) Best configuration by optimization; (b) Worst configuration by optimization; (c) Common sense without optimization.

\subsection{Configuration Optimization for a Special Unbalanced Example}

For unbalanced condition, a particular example: $I_{b}=1.05 I_{a}$ and $I_{c}=1.1 I_{a}$ is studied in this section.

For two unbalanced cables per phase, the best configuration is shown in Figure 7 when phase $c$ is the highest loaded phase and phase $b$ is the medium loaded phase. The second type of cable is selected, and the detailed results are shown in Table 3. 


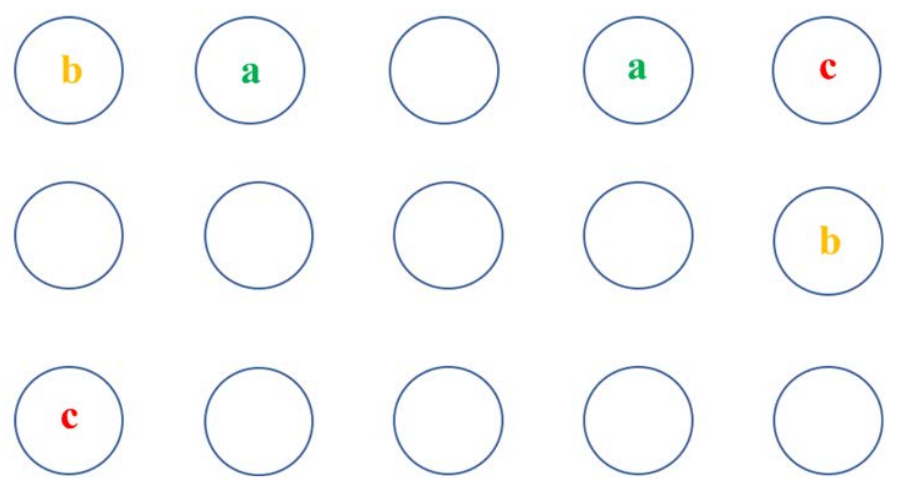

Figure 7. The best configuration for two unbalanced cables per phasein a particular example.

Table 3. Detailed results for two unbalanced cables per phase.

\begin{tabular}{ccc}
\hline Cable \# & Ampacity A & Temperature $^{\circ} \mathrm{C}$ \\
\hline 1b & 651 & 86.9 \\
1a & 620 & 89.4 \\
2a & 620 & 88.7 \\
$1 \mathrm{c}$ & 682 & 87.9 \\
$2 \mathrm{~b}$ & 651 & 87.2 \\
$2 \mathrm{c}$ & 682 & 86.7 \\
\hline
\end{tabular}

For three unbalanced cables per phase, where $c$ is the highest loaded phase, the best configuration based on ampacity is shown in Figure 8, and the detailed results are shown in Table 4.

\subsection{Configuration Optimization for General Unbalanced Condition}

If the highest loaded phase is changed from phase $c$ to phase $b$ and then to phase a, a general pattern for the unbalanced condition is observed, where $\mathrm{H}$ means highest loaded phase; L means lowest loaded phase; $\mathrm{M}$ means medium loaded phase. It is noticed that the best configuration for balanced condition and unbalanced condition based on ampacity is different according to Figure 5(a), Figure 6(a), Figure 9 and Figure 10. But the worst configuration is always arranging all cables near each other.

\section{Conclusion}

Installing cables in ductbanks occurs more and more frequently nowadays since their installation is easy. Use of the full potential of a ductbank is extremely important for reasons of economy. This paper proposes using the optimization method to find the best and worst configuration for cables in a ductbank based on ampacity. The best and worst configurations are decided for both balanced and unbalanced scenarios, which are different from common sense without optimization. For an unbalanced condition, a particular example is studied and 
Table 4. Detailed results for three unbalanced cables per phase.

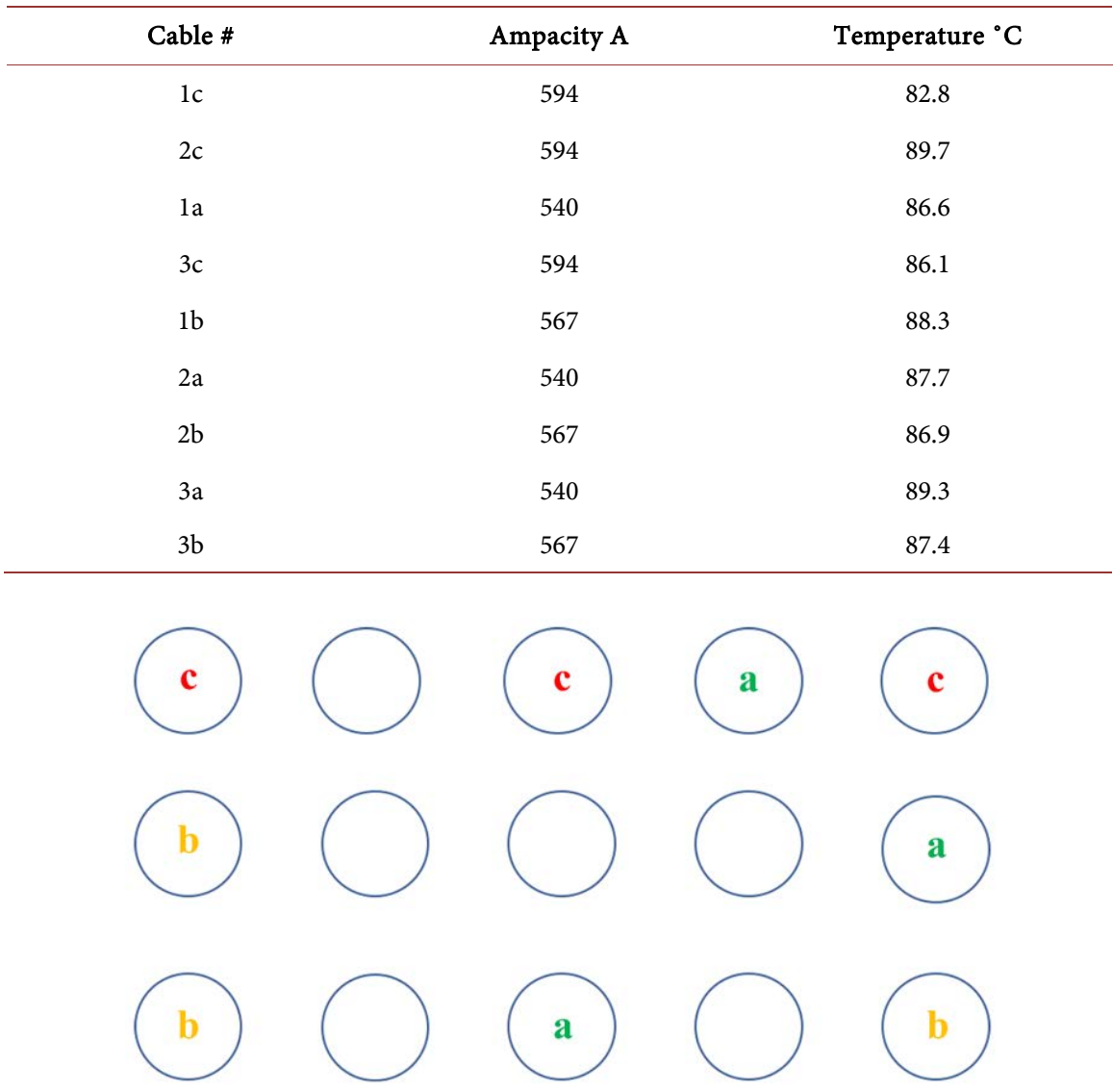

Figure 8. The best configuration for three unbalanced cables per phasein a particular example.
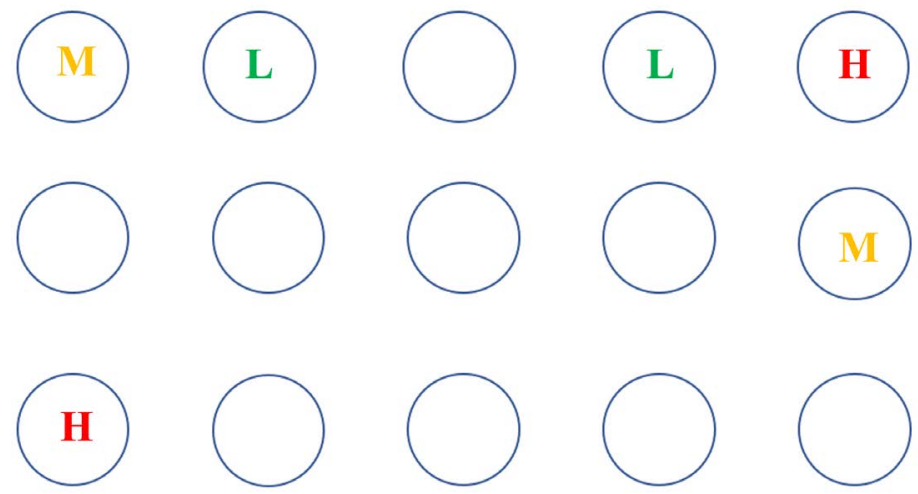

Figure 9. The best configuration for general two unbalanced cables per phase.

then extended to a general pattern for unbalanced cables in a ductbank. In the future, the impacts of optimization during abnormal condition will be discussed. The study will include different faulted phases and loading conditions. Based on the results and conclusion, best case and cable configuration under abnormal condition will be presented. 


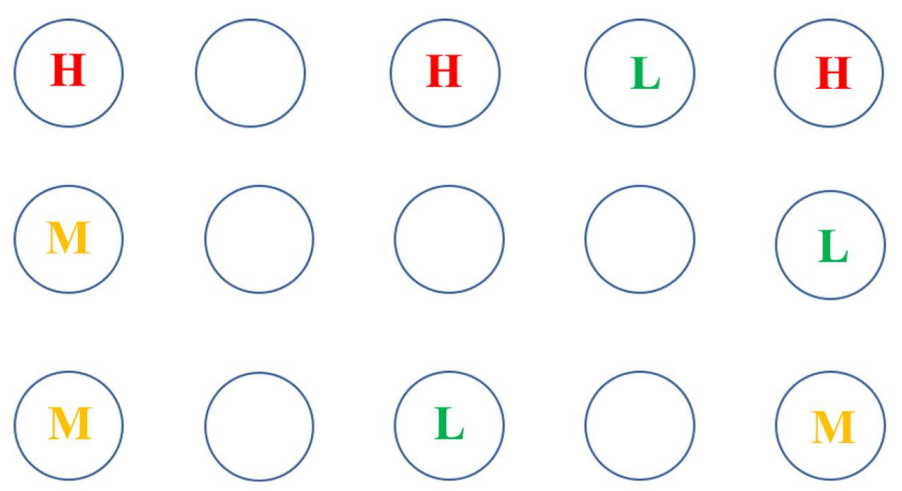

Figure 10. The best configuration for general three unbalanced cables per phase.

\section{Acknowledgements}

The authors would like to thank all the members of the Clemson University Power Research Association (CUEPRA) for their guidance, data and financial support for this research.

\section{References}

[1] Moutassem, W. and Anders, G.J. (2010) Configuration Optimization of Underground Cables for Best Ampacity. IEEE Xplore: IEEE Transactions on Power Delivery, 25, 2037-2045.

[2] Aras, F., Alekperov, V., Can, N. and Kirkici, H. (2007) Aging of 154 kV Underground Power Cable Insulation under Combined Thermal and Electrical Stresses. IEEE Xplore: IEEE Electrical Insulation Magazine, 23, 25-33.

[3] Cichy, A., Sakowicz, B. and Kaminski, M. (2017) Economic Optimization of an Underground Power Cable Installation. IEEE Xplore: IEEE Transactions on Power Delivery, 33, 1124-1133.

[4] Anders, G.J. (1997) Rating of Electric Power Cables: Ampacity Computations for Transmission, Distribution, and Industrial Applications. The Institute of Electrical and Electronics Engineers Press/McGraw-Hill, New York.

[5] Moutassem, W. (2007) Optimization Procedure for Rating Calculations of Unequally Loaded Power Cables. M.S. Thesis, Univ. Toronto, Toronto.

[6] Canova, A., Freschi, F. and Tartaglia, M. (2007) Multiobjective Optimization of Parallel Cable Layout. IEEE Xplore: IEEE Electrical Insulation Magazine, 43, 3914-3920.

[7] Moutassem, W. (2010) Configuration Optimization of Underground Cables inside a Large Magnetic Steel Casing for Best Ampacity. Ph.D. Dissertation.

[8] Haji, M.M., Zarchi, D.A. and Vahidi, B. (2014) Optimal Configuration of Underground Cables to Maximise Total Ampacity Considering Current Harmonics. IET Digital Library: IET Generation, Transmission \& Distribution, 8, 1090-1097.

[9] Advanced Cable Bus Company. http://www.advcablebus.com

[10] Gonen, T. (2013) Electric Power Distribution Engineering. 3rd Edition, CRC Press, Boca Raton.

[11] COMSOL Multiphysics. https://www.comsol.com/

[12] Garrido, C., Otero, A.F. and Cidrás, J. (2003) Theoretical Model to Calculate Steady-State and Transient Ampacity and Temperature in Buried Cables. IEEE 
Transactions on Power Delivery, 18, 667-678. https://doi.org/10.1109/TPWRD.2002.801429

[13] Kansog, J.C. (1994) Ampacity Calculations for Mixed Underground Cable Systems in the Same Ductbank. IEEE Power Engineering Society Transmission and Distribution Conference, Chicago, 10-15 April 1994, 535-543. https://doi.org/10.1109/TDC.1994.328421

[14] Aras, F., Oysu, C. and Yilmaz, G. (2005) An Assessment of the Methods for Calculating Ampacity of Underground Power Cables. Electric Power Components and Systems, 33, 1385-1402. https://doi.org/10.1080/15325000590964425

[15] Klestoff, A.Y. (1988) Current-Carrying Capability for Industrial Underground Cable Installations. IEEE Transactions on Industry Applications, 24, 99-105. https://doi.org/10.1109/28.87258

[16] Neher, J.H. and McGrath, M.H. (1957) The Calculation of the Temperature Rise and Load Capability of Cable Systems. Transactions of the American Institute of Electrical Engineers Part III Power Apparatus and Systems, 76, 752-772.

[17] IEC (2012) Calculation of the Current Rating of Cables.

[18] Diaz-Aguiló, M. and de León, F. (2015) Adaptive Soil Model for Real-Time Thermal Rating of Underground Power Cables. IET Science, Measurement \& Technology, 9, 654-660. https://doi.org/10.1049/iet-smt.2014.0269

[19] CYME International-CYMCAP. http://www.cyme.com/software/cymcap/

[20] Lofberg, J. (2004) YALMIP: A Toolbox for Modeling and Optimization in MATLAB. International Symposium on Computer Aided Control Systems Design, New Orleans, 2-4 September 2004, 284-289.

[21] Kvasnica, M. and Fikar, M. (2010) Design and Implementation of Model Predictive Control Using Multi-Parametric Toolbox and YALMIP. International Symposium on Computer-Aided Control System Design, Yokohama, 8-10 September 2010, 999-1004. https://doi.org/10.1109/CACSD.2010.5612805 


\section{Appendix A. Yalmip Toolbox of MATLAB}

In order to solve the optimization problem, several solver programs have been built, such as Cplex and Gurobi. However, these programs require considerable amounts of time to build optimization models. To build a model quickly, efficient modeling programs and languages are needed. Yalmip is one of the most powerful and convenient toolboxes for mathematical optimization model building [20].

Yalmip is a free MATLAB toolbox for modeling optimization problems. It solves the optimization problem in combination with external solvers. The toolbox simplifies model building of optimization in general and focuses on control-oriented optimization problems in particular [21].

\section{Appendix B. Transfer Ampacity Calculation of an Optimization Problem}

In order to write ampacity calculation equations in an optimization form, the Equations (2)-(6) in Section 2.1 are combined into Equation (1) for cable (1), and the following equation is obtained [4] [5]:

$$
\begin{gathered}
I_{1}=\left[\frac{\Delta \theta_{\max , 1}-W_{d, 1}\left(0.5 T_{1,1}+n_{1}\left(T_{2,1}+T_{3,1}+T_{4,1}\right)\right)}{R_{1} T_{1,1}+n_{1} R_{1}\left(1+\lambda_{1,1}\right) T_{2,1}+n_{1} R_{1}\left(1+\lambda_{1,1}+\lambda_{2,1}\right)\left(T_{3,1}+T_{4,1}\right)}\right. \\
\left.-\frac{n_{2}\left[I_{2}^{2} R_{2}\left(1+\lambda_{1,2}+\lambda_{2,2}\right) \mu_{2}+W_{d 2}\right] * T_{12}+\cdots+n_{n}\left[I_{n}^{2} R_{n}\left(1+\lambda_{1, n}+\lambda_{2, n}\right) \mu_{n}+W_{d n}\right] * T_{1 n}}{R_{1} T_{1,1}+n_{1} R_{1}\left(1+\lambda_{1,1}\right) T_{2,1}+n_{1} R_{1}\left(1+\lambda_{1,1}+\lambda_{2,1}\right)\left(T_{3,1}+T_{4,1}\right)}\right]^{0.5} \\
T_{i j}=\frac{\rho_{s}}{2 \pi} \ln \left(d_{i j}^{\prime} / d_{i j}\right)
\end{gathered}
$$

For all other cables, similar result equations can be obtained as well.

Let

$$
\begin{gathered}
c_{i j}=\frac{n_{j}\left[R_{j}\left(1+\lambda_{1, j}+\lambda_{2, j}\right) \mu_{j}\right] * T_{i j}}{R_{i} T_{1, i}+n_{i} R_{i}\left(1+\lambda_{1, i}\right) T_{2, i}+n_{i} R_{i}\left(1+\lambda_{1, i}+\lambda_{2, i}\right)\left(T_{3, i}+T_{4, i}\right)} \\
d_{i}=\left[\frac{\Delta \theta_{\max , i}-W_{d, i}\left(0.5 T_{1, i}+n_{i}\left(T_{2, i}+T_{3, i}+T_{4}, i\right)-\left(\rho_{s} / 2 \pi\right)\left[\sum N_{j} W_{d, j} \ln \left(d_{i j}^{\prime} / d_{i j}\right)\right]\right)}{R T_{1}+n R\left(1+\lambda_{1}\right) T_{2}+n R\left(1+\lambda_{1}+\lambda_{2}\right)\left(T_{3}+T_{4}\right)}\right]^{0.5}
\end{gathered}
$$

so that the ampacity calculation can be solved as an optimization problem.

\section{Appendix C. Data of Two Types of Cables}

Table C1. Data of first type cable [5].

\begin{tabular}{cccc}
\hline Parameters & Value & Parameters & Value \\
\hline$N$ & 3 & $\rho_{s}$ & 1 \\
$R$ & $0.079 \mathrm{e}-3$ & $W_{d}$ & 0 \\
$\lambda_{1}$ & 0 & $T_{1}$ & 0.341 \\
$\lambda_{2}$ & 0 & $T_{2}$ & 0 \\
$\theta_{\text {anb }}$ & 20 & $T_{3}$ & 0.095 \\
$\theta_{\max }$ & 90 & $T_{4}$ & 0.637 \\
$\mu$ & 1 & $D_{e}$ & 72.9 \\
\hline
\end{tabular}


Table C2. Data of second type cable [5].

\begin{tabular}{cccc}
\hline Parameters & Value & Parameters & Value \\
\hline$N$ & 1 & $\rho_{s}$ & 1 \\
$R$ & $0.0763 \mathrm{e}-3$ & $W_{d}$ & 0 \\
$\lambda_{1}$ & 0 & $T_{1}$ & 0.341 \\
$\lambda_{2}$ & 0 & $T_{2}$ & 0 \\
$\theta_{\text {amb }}$ & 20 & $T_{3}$ & 0.095 \\
$\theta_{\max }$ & 90 & $T_{4}$ & 0.751 \\
$\mu$ & 1 & $D_{e}$ & 35.8 \\
\hline
\end{tabular}

